\title{
Entrepreneurial Orientation and Business Performance of Manufacturing Sector Small and Medium Scale Enterprises of Punjab Pakistan
}

\author{
Syed Hussain Haider ${ }^{1}$, Muzaffar Asad ${ }^{2, *}$, Minaa Fatima ${ }^{3}$ \\ ${ }^{1}$ Strategic Management Division, Akhuwat, Lahore, Pakistan \\ ${ }^{2}$ Teaching Faculty School of Accounting and Finance, Faculty of Management Studies University of Central Punjab, Lahore, Pakistan \\ ${ }^{3}$ P \& D Department, Government of Punjab, Lahore, Pakistan \\ Email address: \\ syedhussainhaider@gmail.com (S. H. Haider),muzaffar.asad@ucp.edu.pk (M. Asad) \\ ${ }^{*}$ Corresponding author
}

\section{To cite this article:}

Syed Hussain Haider, Muzaffar Asad, Minaa Fatima. Entrepreneurial Orientation and Business Performance of Manufacturing Sector Small and Medium Scale Enterprises of Punjab Pakistan. European Business \& Management. Vol. 3, No. 2, 2017, pp. 21-28.

doi: $10.11648 /$ j.ebm.20170302.12

Received: January 10, 2017; Accepted: February 9, 2017; Published: March 24, 2017

\begin{abstract}
Small and Medium Enterprises (SMEs) play an important role in economic growth, innovation, and competitiveness, which ultimately enhances business performance. This study investigated the three dimensions of Entrepreneurial Orientation (EO) of manufacturing sector SMEs in Punjab, Pakistan. In this study the effects of three EO dimensions including innovativeness, pro-activeness, and risk taking have been analyzed with regard to business performance. Questionnaire was used as the main instrument of data collection. Quantitative techniques were applied for analyzing the data. Innovativeness, pro-activeness, and risk taking have a significant impact over business performance of manufacturing sector SMEs. Results further indicated there were positive correlations among innovativeness, pro-activeness and risk taking with business performance of SMEs. This study could be useful for policy makers, owners, and managers to plan their activities for getting better performance of SMEs operating in Punjab, Pakistan.
\end{abstract}

Keywords: SMEs Performance, Manufacturing Sector, Innovativeness, Pro-activeness, Risk Taking, Entrepreneurial Orientation, Manufacturing Sector

\section{Introduction}

For the progress of developing countries promotion of Small and Medium Enterprises (SMEs) is considered as very important. Promotion of SMEs is vital for the economic growth and development of any country [1]. In the underdeveloped countries like Pakistan SME sector has been given least attention by the researchers and practitioners. Despite its economic significance growth rate of SMEs in few developing countries like Pakistan is very slow. SMEs have a significant role towards the economic development of Pakistan. Pakistan is country full of natural resources having an area of $796,094 \mathrm{~km}$ square with a population of 182.1 million masses along with labor force of 57.2 million working in different manufacturing sectors. SMEs of Pakistan have a major contribution towards employment generation, poverty alleviation, and decreasing economic disparity [2]. SMEs in Pakistan contribute significantly to the GDP of the country. The contribution of SMEs towards GDP of the country is almost $30 \%$ [3]. SMEs are operating in all the sectors of the economy including manufacturing sector.

The government of Pakistan, considering the importance of SMEs for the achievement of a balanced economic growth and equitable distribution of wealth has taken several measures to promote SMEs in the country [4]. In the same domain the government has developed Small and Medium Enterprise Development Authority (SMEDA) to promote and strengthen SMEs in the country.

The economic rationale for assisting SMEs is that they often use resources more efficiently than larger enterprises 
[5]. Market imperfections prevent them from maximizing the benefits of their efficiency advantages. They can be an important contributor to pro-poor growth as SMEs have the potential for growth and employment generation [6]. Compared with large firms, SMEs have greater backward linkages to micro-enterprises, and forward subcontracting links to large businesses, making them an important driving force in the economy [7]. SMEs in Pakistan pay higher capital costs and therefore lower wages. The main argument regarding efficiency of SMEs is that most SMEs are managed by their owners and therefore have a greater incentive to manage the capital efficiently.

In this way for sustaining the performance of SMEs, it is fundamental to update the level of business entrepreneurship and existing SMEs to be entrepreneurially orientated [8]. This will mirror their creativity, expert liveliness, and hazard taking qualities, which are especially vital for the growth of business performance of SMEs operating in Pakistan.

Until now little about entrepreneurial activities is known especially in the developing countries like Pakistan. To date, a limited understanding have been developed that why rate of entrepreneurship development vary cross-nationally. This variation is a major issue that needs to be addressed empirically. Basically, researchers have a restricted comprehension regarding why entrepreneurial businesses are more effective in one area than in another. The major reason behind abovementioned issue is lack of entrepreneurial orientation among the entrepreneurs of Pakistan [3]. Similarly, there is limited research dedicated to the field of business enterprises especially regarding the development of enthusiasm of EO among SMEs, especially in developing economies like Pakistan. Investigations regarding entrepreneurial orientation in Pakistan are uncommon and still are at the beginning stage. Therefore, most of the top to bottom studies emphasizing business ought to help in upgrading SME performance without focusing on the importance of entrepreneurial orientation, mainly access to finance have been given attention by majority of the researchers [9]. As of now, huge scale advancement tasks are being actualized to provide fruitful data towards the improvement of business performance of SMEs. Along these lines, empirical studies are expected to better comprehend the level of EO towards better business execution of SMEs in Pakistan.

Another issue regarding the construct of EO which is considered as crucial for the progress of SME sector is that is the construct EO uni-dimensional or multi-dimensional. There are a few debates in the writing with reference to regardless of whether the construct of EO is uni-dimensional or multi-dimensional. Few researchers advocated that EO is best seen as a one-dimensional idea [3]. A few advocated that construct of EO may shift freely, which infers that the impact of multiple individual measurements of EO construct on business performance ought to be emphasized separately. Each measurement of EO construct influence performance distinctively [10]. High innovativeness reveals positive impact over business performance of SMEs [11]. At the same time pro-activeness is emphatically identified to have a significant impact over EO and performance of SMEs [12].

Thus, it is obvious that each and every dimension of EO and EO as a construct is crucial for gaining performance from SMEs. However, in developing countries as mentioned earlier that the research on EO is limited and even the studies that have been conducted have focused EO as a unidimensional construct. Therefore, this study is conducted to find the impact of individual dimensions of EO construct over the performance of manufacturing SMEs in Punjab, Pakistan. The major reason behind choosing manufacturing sector SMEs is that the performance of SMEs in manufacturing sector is declining. The exports of Sports products manufacturing, leather product manufacturing, and surgical instruments manufacturing is continuously declining [13]. These three industries were amongst the top performing manufacturing SMEs in the country in the last decade. The SMEs of these industries were contributing a significant amount in GDP, exports earning, and employment generation.

Considering the importance of each individual dimension of EO, this study focused on the following objectives:

(1) What is the impact of innovativeness over the performance of manufacturing sector SMEs in Punjab, Pakistan?

(2) What is the impact of pro-activeness over the performance of manufacturing sector SMEs in Punjab, Pakistan?

(3) What is the impact of risk taking over the performance of manufacturing sector SMEs in Punjab, Pakistan?

(4) What is the overall impact of EO over the performance of manufacturing sector SMEs in Punjab, Pakistan?

\section{Literature Review}

SMEs are considered as the vehicle of economic growth. SMEs that are entrepreneurially oriented perform better than the others [14]. In this literature review the detailed discussion regarding the three dimensions of entrepreneurial orientation has been discussed in detail. Entrepreneurship focuses on the significance of another passage for business development alluding to the procedure of imaginative annihilation for the development of entrepreneurial orientation [15]. Entrepreneurial businesses are characterized as one that participate in item advertising advancements, attempt to involve in some degree of risky projects, and are first to think of proactive developments for getting better performance [3]. Entrepreneurially oriented businesses are on the off chance as they are creative, good in risk taking, and are considered as proactive [11]. As a rule, entrepreneurial orientation alludes to top administration's system in connection to inventiveness, pro-activeness, and risk taking [16]. EO has been recommended as a fundamental trait of high performing businesses [17]. Various studies have shown that EO ought to be conceptualized as having the three primary attributes innovativeness, risk taking, and proactiveness to evaluate the construct [18]. In today's dynamic 
environment, worldwide, testing business environment requires a business to be entrepreneurial on the off chance that it is a must for survival and development of the businesses [19]. Rapidly changing business environment because of innovation and shortened life cycle of products encourage the requirement to be creative by growing new thoughts, items, and forms, and to adapt the fast change [20]. Expanded competition and worldwide rivalry enhances the requirement for a business to be competitive by becoming innovative [21].

The innovativeness molds the inclination of the businesses to participate in new thoughts and innovative procedures that may bring about new products or services, administrations or mechanical procedures [22]. This innovativeness may have a successful role only if the businesses are proactive, because only proactive businesses can take the first mover advantage [23]. It ensures that up to what level a business is pioneer or devoted and is connected with forceful posing in respect to its competitors [24]. Risk taking is the degree to which a business will make extensive and dangerous decisions by becoming the first mover in the market showing proactiveness [25]. Entrepreneurial SMEs may show all or a portion of the entrepreneurial orientation measurements yet they may contrast in quality and course of relationship. In the same domain the importance of risk taking cannot be ignored. Researchers have identified that risk taking also has a significant impact over the performance of SMEs [24].

Therefore, it is fundamental to apply both a onedimensional and a multi-dimensional construct to deal with EO to comprehend whether every individual dimension of $\mathrm{EO}$ and also general EO is influence business performance or not. In the same context, the hypothetical commitment of this research concentrates on three dimensions of EO excluding the other two dimensions of autonomy and competitive aggressiveness [26]. The dimension of autonomy has been ignored because in Pakistan most of the SMEs are owned and managed by the single owner, the decision making lies with the owner [27]. Thus, this study ought to investigate that up to what extent individual dimensions of EO construct have a positive effect on business performance by the manufacturing sector SMEs operating in Punjab Pakistan.

The arguments raised in the study regarding the importance of innovativeness, risk taking, and pro-activeness support the argument of Resource Based View (RBV) [28]. According to the RBV firm requires resources to gain competitive advantage. EO is amongst the major resource, because in the current era EO is considered as a way of business management which is a resource for the successful operations of the businesses [3]. Based on literature review, most of the studies that have been conducted in Pakistan or any other developing country has studies EO as unidimensional construct $[27,3]$. The main focus of this study is to find the individual impact of the three dimensions of EO namely; innovativeness, pro-activeness, and risk taking. Therefore, this study contributes to the literature by employing the three dimensions of EO construct separately in a developing economy.

\section{Research Methodology}

Research methodology cover the methodology followed by the researcher to conduct research [29]. Research methodology covers the framework of the study along with research design. The framework that has been proposed in this study support RBV of the firm to link the variables that have been selected on the basis of reviewed literature regarding performance of SMEs. The framework that has been proposed in this study is mentioned below:

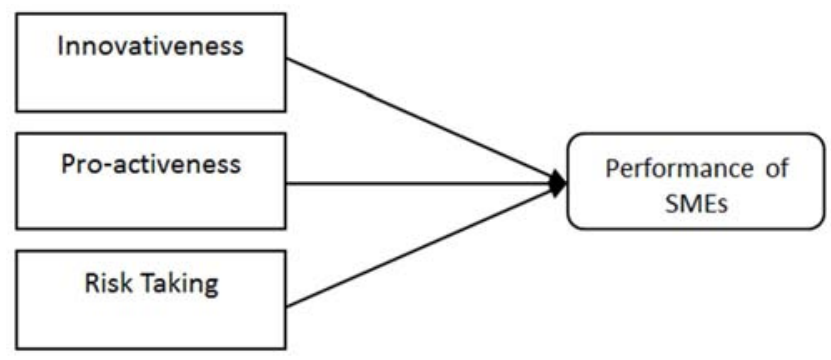

Figure 1. Research Framework.

The abovementioned framework has been proposed on the basis of reviewed literature and RBV for empirical analysis. The independent variables are the three dimensions of EO whereas the dependent variable is the performance of manufacturing sector SMEs in Punjab Pakistan. On the basis of the framework following hypothesis have been developed in the study for empirical testing:

$\mathrm{H}_{1}$ : Innovativeness has a significant impact of performance of Manufacturing SMEs in Punjab Pakistan.

$\mathrm{H}_{2}$ : Pro-activeness has a significant impact of performance of Manufacturing SMEs in Punjab Pakistan.

$\mathrm{H}_{3}$ : Risk Taking has a significant impact of performance of Manufacturing SMEs in Punjab Pakistan.

$\mathrm{H}_{4}$ : EO has a significant impact of performance of Manufacturing SMEs in Punjab Pakistan.

In order to test the hypothesis quantitative analysis has been applied. Quantitative techniques will help to find the impact of dimensions of EO over the performance of SMEs. The study is cross sectional and the data has been collected one point in time [29]. Survey method has been employed as it is considered as best when the opinions of people has to be taken regarding a qualitative measure [30]. The unit of analysis in this study is organization as the performance of manufacturing SMEs have to be measured.

The data has been collected by the use of structured questionnaire. The variables in the questionnaire have been measured on the basis of instrument which was adopted from the previous studies [22, 31]. The variable innovativeness has been measured with seven items, proactivity has been measured with six items, risk taking has been measured with eight items whereas one item of risk taking construct was deleted during factor analysis. The dependent variables that is performance of manufacturing sector SMEs has been measured with a scale of six items. All the variables have been measured using a seven point Likert scale as it increases the sensitivity of the variable and therefore, it is considered 
as more reliable [32]. The reliability and validity of the instrument has been measured with the use of Cronbach's alpha [33].

The results of the study can be generalized if the appropriate population and sampling is done. The population in this study is the entire manufacturing SMEs operating in Punjab. The list of manufacturing sampling was taken from SMEDA and from the sampling frame using SPSS version 22 a sample size of 384 SMEs was chosen. The respondents were sent the questionnaire along with self-addressed stamped envelope.

After receiving the questionnaires the data was entered in SPSS 22 for initial screening. In initial screening, descriptive analysis was done to find the descriptive statistics. The results of descriptive statistics are as follows:

Table 1. Descriptive Analysis.

\begin{tabular}{lllll}
\hline Variables & Mean & SD & Skewness & Kurtosis \\
\hline Performance of SMEs & 4.523 & 0.6885 & 1.405 & 0.283 \\
Innovativeness & 3.589 & 0.9652 & 1.235 & 0.325 \\
Pro-activeness & 4.023 & 0.8542 & 2.352 & 0.421 \\
Risk taking & 4.986 & 0.5246 & 1.964 & 0.359 \\
\hline
\end{tabular}

From the abovementioned table it is clear that the data is normal as the values of Skewness and kurtosis should fall below 3 and 8 respectively [34]. Furthermore, the mean values of all the variables also shows that the level of innovation, pro-activeness, and risk taking is below average which further strengthen the need for study.
After analyzing the descriptive statistics using SPSS 22 and ensuring that the data is normal, structural equation modeling has been applied using PLS-3. Smart PLS 3 has been used as it is considered as best for structural equation modeling. The first thing in Partial Least Square Structural Equation Modeling (PLS SEM) is to measure the construct reliability and validity for ensuing the reliability and validity of the constructs Cronbach's alpha, Average Variance Extracted (AVE), and Composite Reliability (CR) are calculated. The acceptable values for Cronbach's alpha, AVE and $\mathrm{CR}$ are $0.60,0.50$, and 0.70 respectively $[33,35,36]$ which ensures the reliability and validity of the instrument. The calculated values of Cronbach's alpha, CR, and AVE are mentioned below in table 2 :

Table 2. Construct Reliability and Validity.

\begin{tabular}{llll}
\hline Variables & Cronbach's Alpha & CR & AVE \\
\hline Performance of SMEs & 0.899 & 0.922 & 0.662 \\
Innovativeness & 0.917 & 0.934 & 0.672 \\
Pro-activeness & 0.832 & 0.876 & 0.543 \\
Risk taking & 0.946 & 0.956 & 0.755 \\
\hline
\end{tabular}

All the calculated values are above the threshold level, therefore, reliability and validity of the constructs are established. The next step is to calculate factor loading to ensure discriminant validity with the help of Fornell Larcker Criterion [37]. The calculated values of all the items by using Fornell Larcker Criterion are mentioned below in table 3:

Table 3. Outer Loadings.

\begin{tabular}{|c|c|c|c|c|}
\hline Variables & Innovative-ness & Pro-activeness & Risk Taking & Performance of SMEs \\
\hline \multirow{7}{*}{ Innovative-Ness } & 0.750 & & & \\
\hline & 0.846 & & & \\
\hline & 0.811 & & & \\
\hline & 0.739 & & & \\
\hline & 0.903 & & & \\
\hline & 0.869 & & & \\
\hline & 0.890 & & & \\
\hline \multirow{6}{*}{ Pro-Activeness } & & 0.797 & & \\
\hline & & 0.805 & & \\
\hline & & 0.812 & & \\
\hline & & 0.853 & & \\
\hline & & 0.800 & & \\
\hline & & 0.813 & & \\
\hline \multirow{6}{*}{$\begin{array}{l}\text { Risk } \\
\text { Taking }\end{array}$} & & & 0.868 & \\
\hline & & & 0.725 & \\
\hline & & & 0.709 & \\
\hline & & & 0.748 & \\
\hline & & & 0.783 & \\
\hline & & & 0.761 & \\
\hline \multirow{7}{*}{$\begin{array}{l}\text { Performance } \\
\text { of SMEs }\end{array}$} & & & & 0.846 \\
\hline & & & & 0.866 \\
\hline & & & & 0.897 \\
\hline & & & & 0.818 \\
\hline & & & & 0.855 \\
\hline & & & & 0.893 \\
\hline & & & & 0.874 \\
\hline
\end{tabular}


From the abovementioned table it is obvious that the outer model is correct and the factor loadings of all the construct as per the threshold level. To ensure that the constructs are actually measuring what they are supposed to measure discriminant validity is shown in table 4 :

Table 4. Discriminant Validity.

\begin{tabular}{lllll}
\hline Variables & Performance of SMEs & Innova-tiveness & Pro-activeness & Risk Taking \\
\hline Performance & 0.890 & & & \\
Innovativeness & 0.820 & 0.814 & 737 & 0.869 \\
Pro-activeness & 0.608 & 0.581 & 0.62 & \\
Risk taking & 0.653 & 0.586 & & \\
\hline
\end{tabular}

In the above mentioned table all the calculated values are showing discriminant validity as the values of the relevant construct are higher as compared to the other constructs. After ensuring the discriminant modeling the next step is structural equation modeling and hypothesis testing. The table mentioned below shows the structural equation modeling and the results of the hypothesis that have been developed on the basis of problem raised and the literature review with the support of RBV. The figures mentioned below shows direct effects of innovativeness, pro-activeness, and risk taking, showing the beta values and the significance of the independent variables.

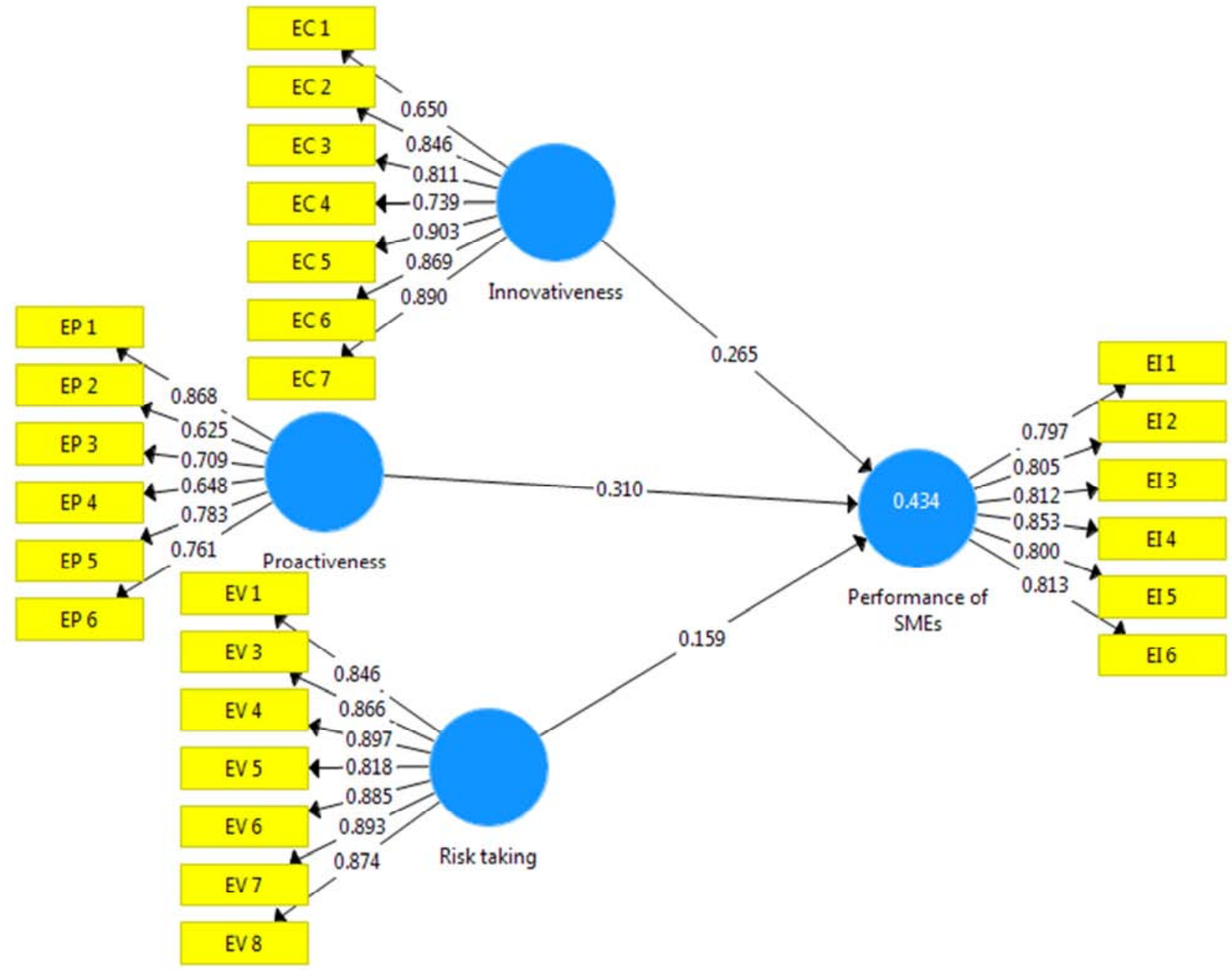

Figure 2. PLS Algorithms.

The above mentioned figure 2 shows PLS algorithms. According to the analysis the direct effects and beta values have been highlighted the figure shows that value of $\mathrm{r}^{2}$ as 0.434 which shows that SPE performance is explained $43.4 \%$ with innovativeness, pro-activeness, and risk taking. In order to find the significance bootstrapping has been conducted which shows the significance of each independent variable. The figure is shown below: 


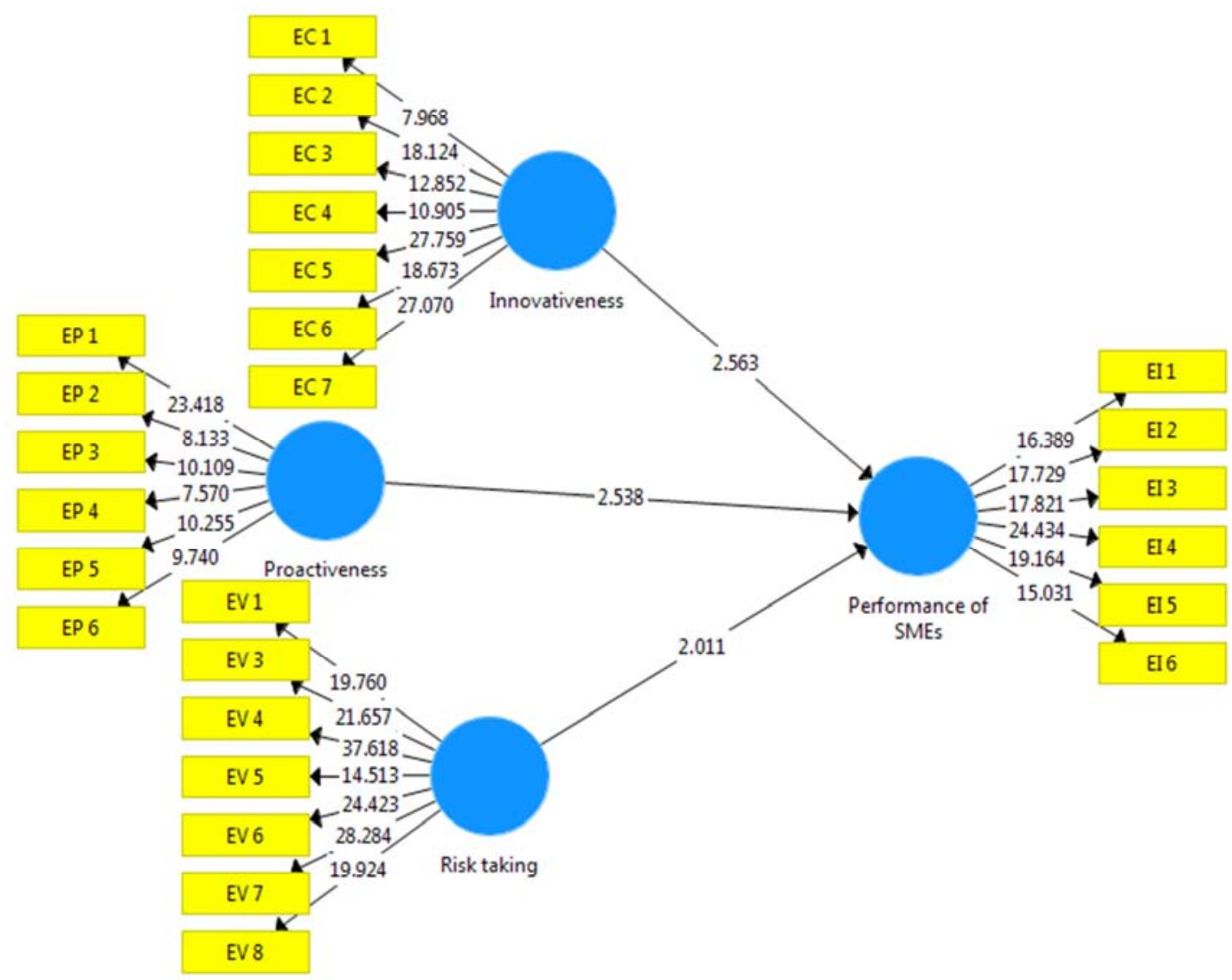

Figure 3. PLS-SEM Bootstrapping.

According to bootstrapping as mentioned above in figure 3 all the independent variables are significant. For further understanding the results for hypothesis testing have been mentioned below in the table:

Table 5. Hypothesis Testing.

\begin{tabular}{llllll}
\hline Variables & Beta & $\begin{array}{l}\text { Sample } \\
\text { Mean }\end{array}$ & SD & $\begin{array}{l}\text { T } \\
\text { Statistics }\end{array}$ & $\begin{array}{l}\text { P } \\
\text { Values }\end{array}$ \\
\hline Innovativeness & 0.265 & 0.267 & 0.169 & 2.563 & 0.012 \\
Pro-activeness & 0.310 & 0.322 & 0.122 & 2.538 & 0.017 \\
Risk taking & 0.259 & 0.156 & 0.157 & 2.011 & 0.031 \\
\hline
\end{tabular}

In the above mentioned table 5 it is obvious that all the independent variables have a significant impact over the performance of manufacturing sector SMEs in Punjab Pakistan. The first independent variable innovativeness is significant as the beta value is 0.265 and it is significant because the value of $\mathrm{T}$ statistics is 2.563 with a $\mathrm{P}$ value of 0.012 . Similarly, the second variable, pro-activeness is also significant because the beta value is 0.310 and the $\mathrm{T}$ statistics are 2.538 with a $\mathrm{P}$ value of 0.017 . Finally, the last independent variable, risk taking is also significant as the beta value is 0.259 with $\mathrm{T}$ statistics as 2.011 and $\mathrm{P}$ value of 0.031 . Therefore, all the hypothesis have been accepted.

\section{Conclusions}

This study was a step towards the support of RBV. The study analyzed the impact of three dimensions of entrepreneurial orientation over the performance of manufacturing sector SME's in Punjab, Pakistan. The level of EO was direct in the dominant part of SMEs in Punjab and there was a noteworthy relationship between inventiveness, pro-activeness, risk taking, and performance of SMEs. Noteworthy positive relationships have been reported showing a positive impact of all the three dimensions that have been studied. The findings facilitated EO construct empirically, related to business performance of manufacturing sector SMEs in Punjab. the findings showed that manufacture sector SMEs if put their efforts on innovation can perform better, likewise, if they are pro-active to market changes they can maintain their performance by maintaining their position in the market. Lastly, risk taking is vital for the growth and performance of SMEs in the manufacturing sector. When the SMEs have to invest in innovation they are exposed to risk which seems to be beneficial for the survival and growth. This study additionally affirms that multidimensionality of EO and identified the individual impact of three common dimensions of EO in a developing economy. The findings of the study are imperative for SMEs to be entrepreneurial with a specific end goal to increment their piece of the pie in the market share by efficient business performance. The findings are further important for the proprietor/managers who are reluctant in becoming creative. The study findings are also important for the policy makers as they guide the policy makers to work on it more efficiently for the development of training centers for 
developing entrepreneurial skills among the owners of SMEs.

In this study the major limitation that was faced while conducting this study include the factors which were not controllable. Especially in the country where this study has been conducted, the issue of energy crisis is at its peak, likewise, the performance of businesses are also adversely affected because of political unrest and law and order situations of the country. All these factors may also influence the performance but were controllable. Furthermore, the study is limited to Punjab only, for future researches it is suggested that the study may be extended to other provinces as well. Another aspect is use of qualitative methods because, qualitative methods may also help in identifying other factors that may affect the performance of manufacturing sector SMEs in the country.

\section{References}

[1] Saeed, S., Yousafzai, S. Y., \& Engelen, A. (2014). On cultural and macroeconomic contingencies of the entrepreneurial orientation-performance relationship. Entrepreneurship Theory and Practice, 38 (2), 255-290. doi:10.1111/etap.12097.

[2] Kongolo, M. (2010). Job creation versus job shedding and the role of SMEs in economic development. African Journal of Business Management, 4 (11), 2288-2295.

[3] Asad, M., Sharif, M. N., \& Hafeez, M. (2016). Moderating effect of network ties on the relationship between entrepreneurial orientation, market orientation, and performance of MSEs. Paradigms A Research Journal of Commerce, Economics, and Social Sciences, 10 (2), 74-81.

[4] Sherazi, S. K., Iqbal, M. Z., Asif, M., Rehman, K. u., \& Shah, S. S. (2013). Obstacles to small and medium enterprises in Pakistan: Principal component analysis approach. Journal of Scientific Research, 13 (10), 1325-1334. doi:10.5829/idosi.mejsr.2013.13.10.1186.

[5] Dougherty, D. (1992). Interpretive Barriers to Successful Product Innovation in Large Firms (Vol. 3).

[6] Aloulou, W., \& Fayolle, A. (2005). A conceptual approach of entrepreneurial orientation within small business context. Journal of Entreprising Culture, 3 (1), 21-45.

[7] Baker, W. E., \& Sinkula, J. M. (2009). The complementary effects of market orientation and entrepreneurial orientation on profitability in small businesses. Journal of Small Business Management, 47 (4), 443-464. doi:10.1111/j.1540627X.2009.00278.x.

[8] Altinay, L., \& Wang, C. L. (2011). The influence of an entrepreneur's socio-cultural characteristics on the entrepreneurial orientation of small firms. Journal of Small Business and Enterprise Development, 18 (4), 673-694.

[9] Wieneke, A., \& Gries, T. (2011). SME performance in transition economies: The financial regulation and firm-level corruption nexus. Journal of Comparative Economics, 39(2), 221-229. doi:10.1016/j.jce.2010.09.001.

[10] Lumpkin, G. T., \& Dess, G. G. (1996). Clarifying the Entrepreneurial Orientation Construct and Linking It To Performance (Vol. 21).
[11] Boso, N., Story, V. M., \& Cadogan, J. W. (2013). Entrepreneurial orientation, market orientation, network ties, and performance: Study of entrepreneurial firms in a developing economy. Journal of Business Venturing, 28 (6), 708-727. doi:10.1016/j.jbusvent.2013.04.001.

[12] Kreiser, P. M., \& Davis, J. (2010). Entrepreneurial orientation and firm performance: The unique impact of innovativeness, proactiveness, and risk-taking. Journal of Small Business \& Entrepreneurship, $23 \quad$ (1), 39-51. doi:10.1080/08276331.2010.10593472.

[13] Wasti, S. E. (2015). Economic Survey of Pakistan 2014-15. Islamabad: Government of Pakistan.

[14] Semrau, T., Ambos, T., \& Kraus, S. (2016). Entrepreneurial orientation and SME performance across societal cultures: An international study. Journal of Business Research, 69 (5), 1928-1932. doi:10.1016/j.jbusres.2015.10.082.

[15] Dai, L., Maksimov, V., Gilbert, B. A., \& Fernhaber, S. A. (2014). Entrepreneurial orientation and international scope: The differential roles of innovativeness, proactiveness, and risk-taking. Journal of Business Venturing, 29 (4), 511-524. doi:10.1016/j.jbusvent.2013.07.004.

[16] Lechner, C., \& Gudmundsson, S. V. (2012). Entrepreneurial orientation, firm strategy and small firm performance. International Small Business Journal, 32 (1), 36-60. doi:10.1177/0266242612455034.

[17] Hznafi, N. B. (2012, June). Business Performance of WomenOwned SMEs in Malaysia: Learning and Entrepreneurial Orientation and the Mediating Role of Competitive Advantage. PhD. Disertation. Sintok, Kedah, Malaysia: University Utara Malaysia.

[18] Simon, M., Stachel, C., \& Covin, J. G. (2011). The effects of entrepreneurial orientation and commitment to objectives on performance. New England Journal of Entrepreneurship, 14 (2), 1-9.

[19] Renko, M., Carsrud, A., \& Brännback, M. (2009). The effect of a market orientation, entrepreneurial orientation, and technological capability on innovativeness: A study of young biotechnology ventures in the United States and in Scandinavia. Journal of Small Business, 47 (3), 331-369. doi:10.1111/j.1540-627X.2009.00274.x.

[20] Rhee, J., Park, T., \& Lee, D. H. (2010). Drivers of innovativeness and performance for innovative SMEs in South Korea: Mediation of learning orientation. Technovation, 30 (1), 65-75. doi:10.1016/j.technovation.2009.04.008.

[21] Rubera, G., \& Kirca, A. H. (2012). Firm innovativeness and its performance outcomes: A meta-analytic review and theoretical integration. Journal of Marketing, 76 (3), 130-147. doi:http://dx.doi.org/10.1509/jm.10.0494.

[22] Boso, N., Cadogan, J. W., \& Story, V. M. (2012). Entrepreneurial orientation and market orientation as drivers of product innovation success: A study of exporters from a developing economy. International Small Business Journal. doi:10.1177/0266242611400469.

[23] Lumpkin, G., Cogliser, C. C., \& Schneider, D. R. (2009). Understanding and measuring autonomy: An entrepreneurial orientation perspective. Entrepreneurship Theory and Practice, 33 (1), 47-69. doi:10.1111/j.15406520.2008.00280.x. 
[24] Kreiser, P. M., Marino, L. D., Kuratko, D. F., \& Weaver, K. M. (2013). Disaggregating entrepreneurial orientation: The nonlinear impact of innovativeness, proactiveness and risk-taking on SME performance. Small Business Economics, 40(2), 273291. doi:10.1007/s11187-012-9460-x

[25] Brettel, M., Chomik, C., \& Flatten, T. C. (2015). How organizational culture influences innovativeness, proactiveness, and risk-taking: Fostering entrepreneurial orientation in SMEs. Journal of Small Business Management, 53(4), 868-885. doi:10.1111/jsbm.12108

[26] Rauch, A., Wiklund, J., Lumpkin, G., \& Frese, M. (2009). Entrepreneurial orientation and business performance: An assessment of past research and suggestions for the future. Entrepreneurship Theory and Practice, 33(3), 761-787. doi:10.1111/j.1540-6520.2009.00308.x

[27] Akhtar, C. S., Ismail, K., Hussain, J., \& Umair-ur-Rehman, M. (2015). Investigating the moderating effect of family on the relationship between entrepreneurial orientation and success of enterprise: Case of Pakistani manufacturing SMEs. International Journal of Entrepreneurship and Small Business, 26(2).

[28] Wernerfelt, B. (1984). A resource-based view of the firm. Strategic Management Journal, 50(2), 171-180. doi:10.1002/smj.4250050207

[29] Zikmund, W., Babin, B., Carr, J., \& Griffin, M. (2012). Business Research Methods. Masson: Cengage Learning.

[30] Creswell, J. (2013). Research Design: Qualitative,
Quantitative, and Mixed Methods Approaches. Chicago: SAGE Publications.

[31] Kraus, S., Rigtering, J. P., Hughes, M., \& Hosman, V. (2012). Entrepreneurial orientation and the business performance of SMEs: A quantitative study from the Netherlands. Review of Managerial Science, 6(2), 161-182.

[32] Cooper, D. R., \& Schindler, P. S. (2006). Business Research Methods. Chicago: McGraw-Hill Irwin.

[33] Gardner, P. L. (1998). Measuring attitudes to science: Unidimensionality and internal consistency revisited. Research in Science Education, 25(3), 283-289. doi:10.1007/BF02357402

[34] Kline, R. B. (2005). Principles and Practice of Structural Equation Modeling. New York: The Guilford Press.

[35] Henseler, J., \& Chin, W. W. (2010). A comparison of approaches for the analysis of interaction effects between latent variables using partial least squares path modeling. Structural Equation Modeling: A Multidisciplinary Journal, 17(1), 82-109. doi:10.1080/10705510903439003

[36] Hair, J. F., Sarstedt, M., Ringle, C. M., \& Mena, J. A. (2012). An assessment of the use of partial least squares structural equation modeling in marketing research. Journal of the Academy of Marketing Science, 40(3), 414-433. doi:10.1007/s11747-011-0261-6

[37] Joseph F. Hair, J., Hult, G. T., Ringle, C., \& Sarstedt, M. (2013). A Primer on Partial Least Squares Structural Equation Modeling (PLS-SEM). SAGE Publications. 